\title{
¿Potential Socioeconomic and Environmental Benefits and Beneficiaries of UAS Atmospheric Profiles from a 3D Mesonet
}

\author{
Christopher A. Fiebrich, ${ }^{\mathrm{a}}$ Jadwiga R. Ziolkowska, ${ }^{\mathrm{b}}$ Phillip B. Chilson, ${ }^{\mathrm{c}, \mathrm{d}}$ AND \\ Elizabeth A. Pillar-LitTle ${ }^{\mathrm{d}}$ \\ ${ }^{a}$ Oklahoma Mesonet, Oklahoma Climatological Survey, School of Meteorology, University of Oklahoma, Norman, Oklahoma \\ ${ }^{\mathrm{b}}$ Department of Geography and Environmental Sustainability, University of Oklahoma, Norman, Oklahoma \\ ${ }^{\mathrm{c}}$ Advanced Radar Research Center, School of Meteorology, University of Oklahoma, Norman, Oklahoma \\ ${ }^{\mathrm{d}}$ Center for Autonomous Sensing and Sampling, School of Meteorology, University of Oklahoma, Norman, Oklahoma
}

(Manuscript received 3 September 2020, in final form 18 February 2021)

\begin{abstract}
In recent years, technological developments in engineering and meteorology have provided the opportunity to introduce innovative extensions to traditional surface mesonets through the application of uncrewed aircraft systems (UAS). This new approach of measuring vertical profiles of weather variables by means of UAS in the atmospheric boundary layer, in addition to surface stations, has been termed a 3D mesonet. Technological innovations of a potential 3D mesonet have recently been described in the literature. However, a broader question remains about potential socioeconomic and environmental benefits and beneficiaries of this new extension. Given that the concept of a 3D mesonet is a new idea, studies about socioeconomic and environmental advantages of this network (as compared with traditional mesonets) do not appear to exist in the peer-reviewed literature. This paper aims to fill this gap by providing a first perspective on potential benefits and ripple effects of a 3D mesonet, addressing both the added value and prevented losses in specific sectoral applications and for different groups. A better understanding of qualitative economic aspects related to a 3D mesonet can facilitate future developments of this technology for more cost-effective applications and to mitigate environmental challenges in more efficient ways.
\end{abstract}

KEYWORDS: Boundary layer; Inversions; Air quality; Mesoscale processes; Aircraft observations; Automatic weather stations

\section{Introduction}

In 2009, The National Research Council set out to develop a vision for "an integrated, flexible, adaptive, and multipurpose mesoscale meteorological observation network; and to identify specific steps to help to develop a network that meets multiple national needs in a cost-effective manner." The resulting report, Observing Weather and Climate from the Ground Up: A Nationwide Network of Networks (National Research Council 2009), identified that profiles of the lower troposphere are "too limited in what they measure, too sparsely or unevenly distributed, frequently limited to regional areal coverage, and clearly do not qualify as a mesoscale network of national dimensions." The report detailed that the highest priority observations included measurements of the height of the planetary boundary layer and high-resolution vertical profiles of humidity, while the second tier of needed observations included vertical profiles of wind and temperature.

More recent reports have also indicated the need for increased measurements in the atmospheric boundary layer (ABL; i.e., the bottom layer of the troposphere that is in contact with Earth's surface) to improve situational awareness and weather forecasting skill. For example, the National

¿ Denotes content that is immediately available upon publication as open access.

Corresponding author: Christopher A. Fiebrich, fiebrich@ou.edu
Academies of Science, Engineering, and Medicine's report, Thriving on Our Changing Planet: A Decadal Strategy for Earth Observations from Space, listed the development of a better understanding of ABL processes as among the "most important" topics for further study over the next 10 years [National Academies of Sciences, Engineering, and Medicine (NASEM) 2018a]. The importance of enhanced ABL measurements, especially with regard to how they should be coupled with modeling studies, was also stressed in The Future of Atmospheric Boundary Layer Observing, Understanding, and Modeling: Proceedings of a Workshop (NASEM 2018b).

Statewide and regional-scale surface mesonets [defined by Fiebrich et al. (2020) as automated and fixed stations that record measurements of air temperature, relative humidity, solar radiation, precipitation, wind speed and direction, pressure, soil temperature, and soil moisture on, or adjacent to, a 10-m tower; Fig. 1] have expanded in coverage across the United States since the 1990 s, with at least 28 operational networks cataloged by Mahmood et al. (2017; Fig. 2). From a meteorological perspective, the term "mesoscale" is generally used to describe atmospheric phenomena having spatial and temporal scales ranging from a few to several hundred kilometers and from a few minutes to 1 day, respectively (American Meteorological Society 2020).

Mesonets continue to show value, not only from a meteorological point of view (e.g., by providing trusted and real-time data, decadal archives of weather changes) but also as a basis for decision-making (Hocker et al. 2018) and determining the value of highly variable yet intangible information. Because of 


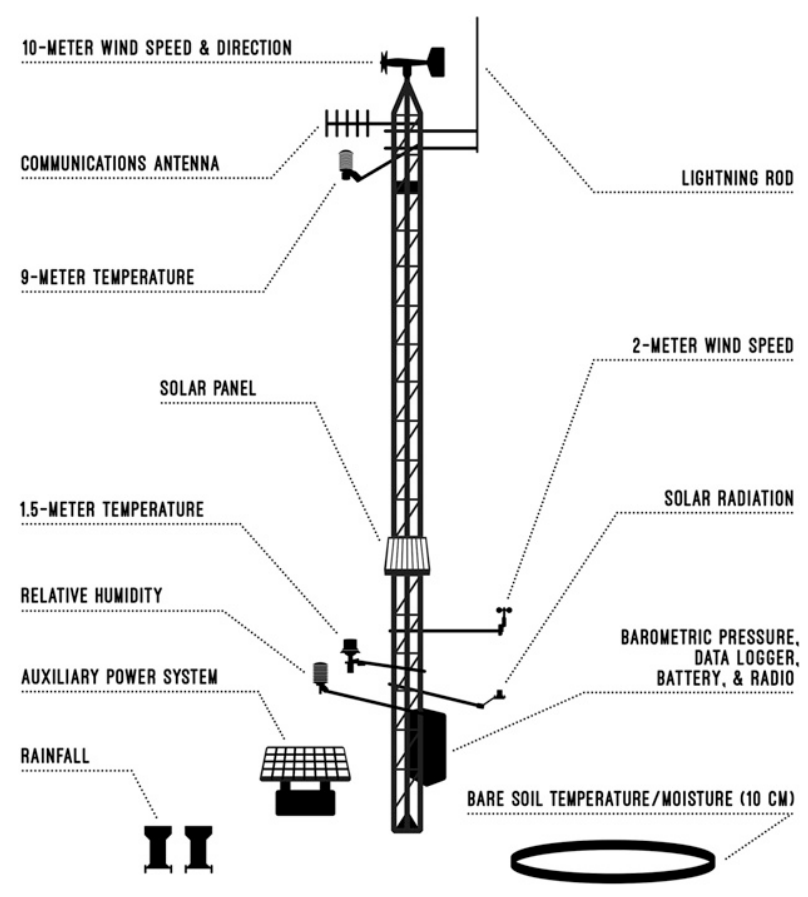

SOIL TEMPERATURE/MOISTURE $(5,10,25, \& 60 \mathrm{CM})$

FIG. 1. Diagram of a typical surface mesonet station.

the challenging nature of determining the real value of weather information (i.e., benefits of information in tangible and measurable terms), studies related to economic evaluations of mesonets have been scarce over the years, although greatly needed for practical and scientific purposes. Because of the wide use of mesonet observations by decision-makers in numerous sectors (e.g., agriculture, public safety, and weather forecasting), several studies have assessed the economic benefits and beneficiaries of traditional surface mesonet data (Ziolkowska et al. 2017), as well as the economic value of mesonet information (Ziolkowska 2018; Ziolkowska and Zubillaga 2018).

In technological terms, while most regional and statewide mesonets have relied on surface measurements, two mesonets, namely, the West Texas Mesonet and the New York State Mesonet, have added atmospheric profile measurements at a subset of locations, via the deployment of lidar, radiometers, or sodars (Schroeder et al. 2005; Brotzge et al. 2018). In recent years, the use of small uncrewed aircraft systems (sUAS) has increased across a variety of disciplines, such as agriculture, surveying and infrastructure inspection, emergency management, law enforcement, parcel deliveries, and videography. The adoption of sUAS technology across a wide variety of industries has led both the National Aeronautics and Space Administration (NASA) and the Federal Aviation Administration (FAA) to discuss and design approaches for how to best develop an sUAS Traffic Management System (UTM) that will allow sUAS to integrate seamlessly with the National Airspace System (NAS; Aweiss et al. 2018). Much of the research on this topic has focused on "detect and avoid" technologies such as computer vision algorithms (Sarim et al. 2019) or radars. However, meso- to microscale weather structures must also be considered as an important factor in sUAS operation in the NAS. Much like their larger crewed counterparts, sUAS are prone to dramatic destabilization in-flight by windshear and turbulence. The safe operation of sUAS inherently relies on improved ABL characterization through expanded vertical profile measurements that the sUAS themselves are uniquely capable of achieving. Moreover, accurate profiles of thermodynamic variables are necessary to characterize the buoyancy of an air mass, which can provide insight into small-scale updrafts and downdrafts that could likewise endanger sUAS traversing the NAS.

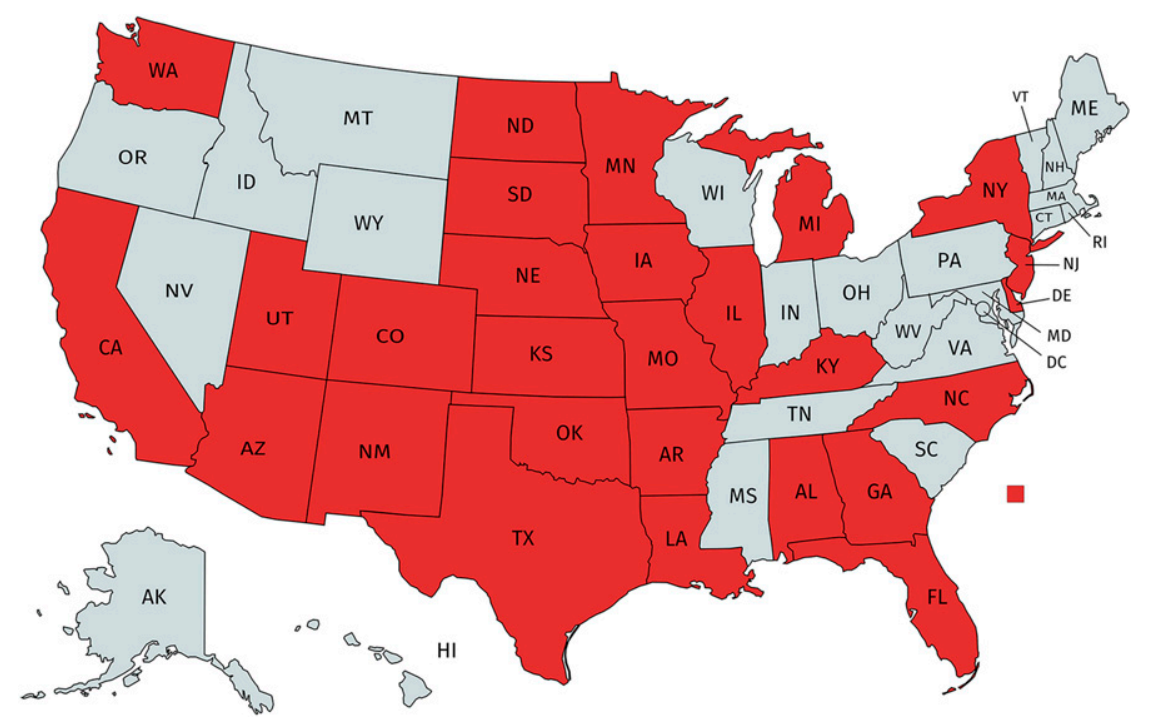

FIG. 2. Location of statewide mesonets (highlighted in red) cataloged by Mahmood et al. (2017). 


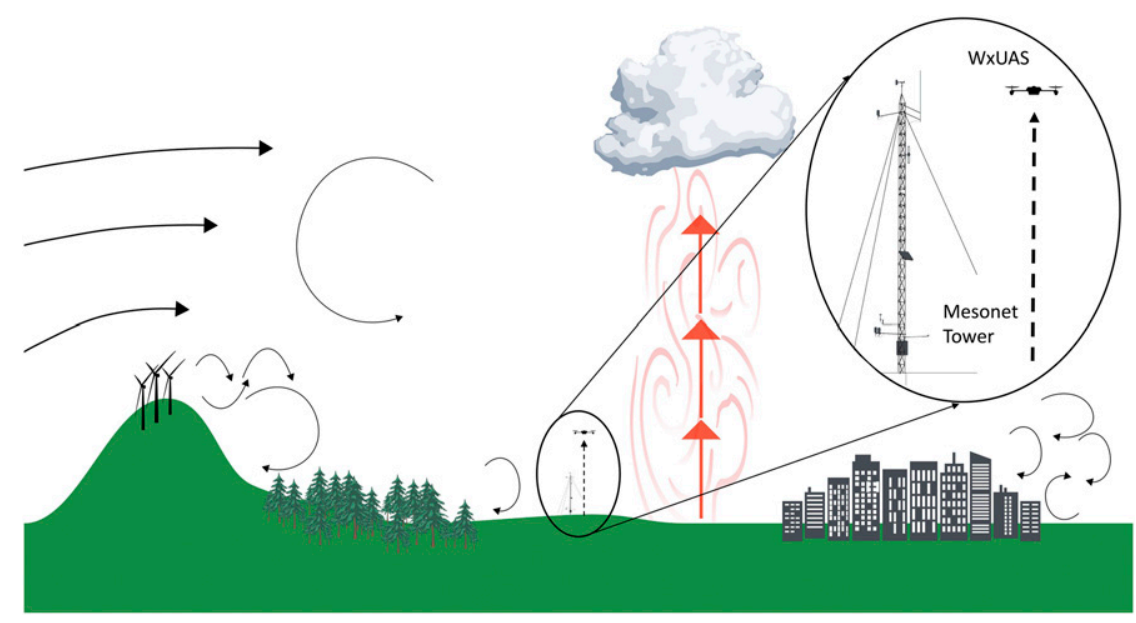

FIG. 3. Depiction of a 3D mesonet observing system including a standard 10-m surface mesonet tower along with a WxUAS capable of sampling the complex kinematic and thermodynamic structure of the ABL.

Glasheen et al. (2019) recently provided forecasting support to an sUAS flight campaign in south central Colorado. The authors found that the 100-m gridded WRF-LES model that was initialized using high-resolution model outputs regularly underestimated the observed temperature, relative humidity, and wind speed. This suggests that more information is needed on a meso- to microscale level that extends into the airspace that can more accurately describe the perturbations throughout the ABL. To address this scientific and practical need, Chilson et al. (2019) described a novel concept of systematically expanding traditional surface mesonet measurements into the vertical direction through the deployment of sUAS specifically developed for weather measurements, known as weather-observing UAS (WxUAS). An example of a system designed to make such measurements is the CopterSonde. A discussion of the CopterSonde, the accuracy of the data, and typical sampling strategies can be found in Segales et al. (2020), Bell et al. (2020), and Pillar-Little et al. (2021). This concept applies the generally known technology of sUAS to a new area of meteorology and climatology, hereinafter referred to as a $3 D$ mesonet. The goal of such a $3 \mathrm{D}$ mesonet is to improve the observations of detailed profiles of temperature, moisture, and winds within the ABL. Figure 3 depicts the complex wind fields of the ABL that are generated from topography, land use (e.g., forests, urban structures), and convection.

While WxUAS technology is still new for the application in this area, and no known mesonets have yet deployed WxUAS in an operational nature to collect such mesoscale observations, rapid developments are taking place. These developments encompass both the technological aspects of the WxUAS itself and the practical (though still little explored) aspects of their application. In this context, an important question arises about the economics of WxUAS at large, economics of combining the new data with traditional surface mesonet observations, potential benefits and beneficiaries of this practical new application, and the potential ripple effects in different economic sectors and different societal groups now and in the future.
A qualitative economic analysis of potential benefits and beneficiaries of a 3D mesonet does not exist as of now. Through this paper, we aim to provide added-value knowledge to facilitate future developments of WxUAS from the perspective of technological developments and practical applications. We readily acknowledge there are several engineering and regulatory challenges to overcome before a functioning $3 \mathrm{D}$ mesonet can be fully realized. Some of these are outlined in Chilson et al. (2019). In particular, careful attention must be given to risk mitigation and airspace deconfliction to satisfy safety requirements established by the FAA in the United States or corresponding Civil Aviation Authorities (CAA) in other countries. Therefore, it is important to carefully assess the potential impacts that a $3 \mathrm{D}$ mesonet could have on a variety of public sectors, such as weather forecasting, agriculture, energy, and health. The goal of this paper is to explore and qualitatively analyze potential socioeconomic and environmental benefits as well as possible beneficiaries of atmospheric profiles from a 3D mesonet that might soon be integrated into the operational data streams of surface mesonets across the United States. Other aspects of economics related solely to technological sustainability of WxUAS are not addressed here.

\section{History of UAS use in meteorology for profiling}

The National Weather Service radiosonde network consists of 92 observation locations across North America and the Pacific Islands that take twice-daily profiles of the atmosphere up to approximately $12 \mathrm{~km}$ (Durre et al. 2006). Because of the coarse sampling of the radiosonde network in both time and space, many atmospheric conditions and processes are undersampled, especially in the dynamic ABL (Chilson et al. 2019). An increasing number of studies have shown the need for more observations of the ABL (NASEM 2018a; Carbone et al. 2012; Vömel et al. 2018). These needs have been addressed in part using technologies such as wind profiling radars, sodars, lidars, 
and radiometers (NASEM 2018b); however, the "data gap" still persists.

The initial application of WxUAS for meteorological studies was achieved via fixed-wing aircraft (Elston et al. 2015). These aircraft successfully made targeted observations of meteorological phenomena otherwise too small in scale to be sampled or too difficult to access by traditional radiosondes. Examples of WxUAS applications in the atmospheric sciences include the characterization of mesoscale airmass boundaries (Houston et al. 2012), Arctic studies (Crowe et al. 2012; de Boer et al. 2019), measurements of heat flux related to surface-atmosphere coupling (Lee et al. 2017; Bonin et al. 2013; Båserud et al. 2020), atmospheric boundary layer transitions (Bonin et al. 2013; Lothon et al. 2014), convection initiation (Koch et al. 2018), wind energy (Reuder et al. 2016), and hurricanes (Cione et al. 2020).

Because of engineering advancements and miniaturization in UAS technology, rotary-wing WxUAS capable of making automated profile measurements are rapidly being prototyped and characterized (Brosy et al. 2017; Hemingway et al. 2017; Greene et al. 2018, 2019; Segales et al. 2020; Bell et al. 2020; Leuenberger et al. 2020). Despite the acceleration in UAS development and its application for atmospheric research, overwhelmingly, the reported studies have been limited in scope. The deployment of robust and hardened WxUAS during routine and situationally targeted observations of the atmosphere shows great promise to advance our understanding of weather, climate, and hydrologic processes, as well as benefit multiple economic sectors.

\section{Technical characteristics of WxUAS in mesonets}

The potential added-value benefits of applying WxUAS in mesonets are promising on several accounts: by increasing the number of atmospheric variables measured, by expanding the dimension of the measurements into the ABL (i.e., upward of 1-2 km), and by providing validation and diagnostic data for traditional surface mesonets. Table 1 compares the most common mesonet measurements along with the typical technology and protocols for observing those same measurements via WxUAS.

There are several unique differences in the characteristics of 3D mesonet observations as compared to standard surface mesonet observations. For instance, while standard mesonet observations are typically made with a temporal resolution of $5 \mathrm{~min}$ over spatial scales of approximately $30 \mathrm{~km}$ (Mahmood et al.2017), 3D mesonet profiles will likely be on a coarser time scale of hourly and over a spatial scale of approximately $100 \mathrm{~km}$. This resolution would still be a significantly finer resolution than the existing radiosonde network, which consists of synoptic measurements made every $12 \mathrm{~h}$ over a spatial scale of approximately $500 \mathrm{~km}$.

There are a number of options for flight patterns of future WxUAS at established mesonet locations. We envision the most likely protocol would be for short, vertical profiles (e.g., launching from the ground near the mesonet station and climbing upward for 1-2 km as measurements are recorded and then descending directly down to the launch location).
Given that more delicate, miniaturized versions of sensors are required to meet the weight and power requirements to optimize the performance of WxUAS, the sensors are typically less rugged than those mounted on standard mesonet stations.

\section{Benefits, beneficiary groups, and ripple effects of $3 D$ mesonet information}

Both technological developments of WxUAS and its practical applications in different areas of weather monitoring are instigating aspects to a broader question of socioeconomic and environmental benefits that can possibly arise as short-term, midterm, or long-term outcomes of incorporating this technology into traditional surface mesonets. This paper presents a first attempt (according to the authors' knowledge) to delineate and analyze these benefits for different beneficiary groups and different economic sectors, as well as potential (intended or unintended) impacts on other sectors (i.e., ripple effects). Figure 4 highlights the relationship between the various beneficiaries, benefits, and ripple effects. In the following sections, we outline six sectors that are most likely to benefit given the potential of 3D mesonet observations becoming available: weather forecasting and nowcasting, the agricultural sector, wildland fire management, public health and air quality, wind energy, and climate monitoring.

The analysis in this paper will consider three groups of economic benefits and ripple effects: direct impacts (e.g., benefits/ripple effects in a given sector of the initial application), indirect impacts (e.g., in other economic sectors than the sector of application), and induced impacts (e.g., impacts resulting from changes in human spending behavior and welfare across different economic sectors). In addition to providing new scientific added-value information in the literature, this paper's analytical discussion of potential benefits, beneficiaries, and ripple effects of WxUAS has the following objectives: (i) to improve the understanding and increase awareness of current and potential future advantages of WxUAS, which could further facilitate investments and developments (i.e., both in science/research and practical deployments/applications), thus generating short-term and midterm societal and economic benefits; and (ii) to uncover open questions and yet undiscussed challenges and opportunities.

This paper does not aim to provide a quantitative evaluation of benefits. Because of the early developments and applications of WxUAS in the field of meteorological monitoring, no robust data are available at this time to proceed with monetary assessments. However, it is expected that this kind of a quantitative analysis will be possible in the near future. Rather, this paper aims to provide an analytical discussion and a tangible assessment of benefits provided by WxUAS technology that can further advance other economic sectors and prevent negative environmental impacts. It is clear that the added value of WxUAS observations will need to be assessed against more conventional means of monitoring the ABL. However, we posit that overall societal welfare can be optimized through improved knowledge generation and application, accessibility and dissemination of more precise and accurate information, 
TABLE 1. Comparison of common technologies used for measurements in traditional surface mesonets and WxUAS.

\begin{tabular}{|c|c|c|c|}
\hline Measurement & $\begin{array}{l}\text { Traditional surface mesonet } \\
\text { technology and protocols }\end{array}$ & WxUAS technology and protocols & Notes \\
\hline Air temperature & $\begin{array}{l}\text { Thermistor mounted in a radiation } \\
\text { shield at } 1.5-2.0 \mathrm{~m}\end{array}$ & $\begin{array}{l}\text { Thermocouple or thermistor } \\
\text { positioned on the WxUAS }\end{array}$ & $\begin{array}{l}\text { Care must be taken to avoid } \\
\text { radiational heating and heating } \\
\text { from the UAS motor }\end{array}$ \\
\hline Relative humidity & $\begin{array}{l}\text { Thin-film capacitive hygrometer, } \\
\text { mounted in a radiation shield at } \\
1.5-2.0 \mathrm{~m}\end{array}$ & $\begin{array}{l}\text { Thin-film capacitive hygrometer } \\
\text { positioned on the WxUAS }\end{array}$ & $\begin{array}{l}\text { Capacitive membrane is known to } \\
\text { degrade over time because of } \\
\text { imbedding of dirt and debris }\end{array}$ \\
\hline Solar radiation & $\begin{array}{l}\text { Thermopile or silicone photovoltaic } \\
\text { sensor mounted on a boom on } \\
\text { the tower }\end{array}$ & Not typically measured & \\
\hline Precipitation & Unheated tipping-bucket gauge & Not typically measured & \\
\hline Wind speed & $\begin{array}{l}\text { Cup or propeller anemometer, } \\
\text { mounted at the top of the } \\
10 \text {-m tower }\end{array}$ & $\begin{array}{l}\text { Measured directly from sensors } \\
\text { mounted on the WxUAS or } \\
\text { derived from WxUAS diagnostics } \\
\text { (i.e., pitch, yaw, and roll angle) }\end{array}$ & \\
\hline Wind direction & $\begin{array}{l}\text { Potentiometer mounted at the top of } \\
\text { the } 10-\mathrm{m} \text { tower }\end{array}$ & $\begin{array}{l}\text { Measured directly from sensors } \\
\text { mounted on the WxUAS or } \\
\text { derived from WxUAS diagnostics } \\
\text { (i.e., pitch, yaw, and roll angle) }\end{array}$ & \\
\hline $\begin{array}{l}\text { Atmospheric } \\
\text { pressure }\end{array}$ & $\begin{array}{l}\text { Capacitive barometer positioned } \\
\text { inside enclosure mounted on tower }\end{array}$ & $\begin{array}{l}\text { Barometer chip positioned in } \\
\text { WxUAS autopilot system }\end{array}$ & \\
\hline Soil temperature & $\begin{array}{l}\text { Thermistor buried adjacent to the } \\
\text { tower, typically at } 5-10 \mathrm{~cm}\end{array}$ & Not typically measured & $\begin{array}{l}\text { Could be derived from infrared } \\
\text { temperature sensor mounted } \\
\text { below WxUAS }\end{array}$ \\
\hline Carbon dioxide & Not typically measured & $\begin{array}{l}\text { Nondispersive infrared (NDIR) } \\
\text { sensor }\end{array}$ & $\begin{array}{l}\text { Reported concentrations must be } \\
\text { corrected for pressure deviations } \\
\text { with altitude (Kunz et al. 2018) }\end{array}$ \\
\hline Ozone & Not typically measured & $\begin{array}{l}\text { Electrochemical sensors } \\
\quad \text { (Zielke 2011) }\end{array}$ & $\begin{array}{l}\text { Voltage output must be calibrated } \\
\text { against laboratory or in situ } \\
\text { spectrophotometer }\end{array}$ \\
\hline $\mathrm{NO}_{x}$ & Not typically measured & Electrochemical sensors & $\begin{array}{l}\text { Voltage output must be calibrated } \\
\text { against laboratory or in situ } \\
\text { spectrophotometer (Ahlawat } \\
\text { et al. 2019) }\end{array}$ \\
\hline Particulate matter & Not typically measured & $\begin{array}{l}\text { Optical particle counter (Brady et al. } \\
\text { 2016; Alvarado et al. 2017) }\end{array}$ & $\begin{array}{l}\text { Inlet placement must ensure sample } \\
\text { is drawn from air undisturbed by } \\
\text { propeller wash; some applications } \\
\text { may require chemical driers to } \\
\text { decrease water adsorbed onto } \\
\text { particles }\end{array}$ \\
\hline
\end{tabular}

new intellectual property, and added-value of these applications in the field of meteorology and climatology.

\section{a. Weather forecasting and nowcasting}

An improvement in weather forecasting and nowcasting has the potential to impact the daily life activities of individuals (Stewart et al. 2012) and virtually every major sector of the U.S. economy (Lazo et al. 2011). There are many factors that enable a successful forecast, including the availability of quality atmospheric measurements, especially in the ABL (McFarquhar et al. 2020). One of the first demonstrations of how WxUAS data can be used to validate finescale numerical simulations took place during the Flow Over and Around Hofsjökull (FLOHOF) campaign in Iceland (Mayer et al. 2012). The Small Unmanned Meteorological Observer (SUMO; Reuder et al. 2009) was used to collect height profiles of thermodynamic and kinematic atmospheric parameters from the surface up to roughly $3-3.5 \mathrm{~km}$ above ground level. More recently, Leuenberger et al. (2020) reported that numerical weather forecasts were improved through combined lidar and WxUAS observations to fill the low-altitude data gap. During the Environmental Profiling and Initiation of Convection (EPIC) project conducted in Oklahoma in May 2018, the value of using fixed- and rotarywing WxUAS to evaluate prestorm environments was demonstrated (Koch et al. 2018). Rotary-wing WxUAS were operated in a profiling mode at two Oklahoma Mesonet sites, while fixed-wing WxUAS flew transects between the sites. Such data enabled the monitoring of capping inversions, lowlevel moisture flow, directional wind shear, and atmospheric buoyancy. Other applications that call for improved low-altitude data collection are the prediction of winter precipitation type (Tripp et al. 2021) and fog forecasts. 


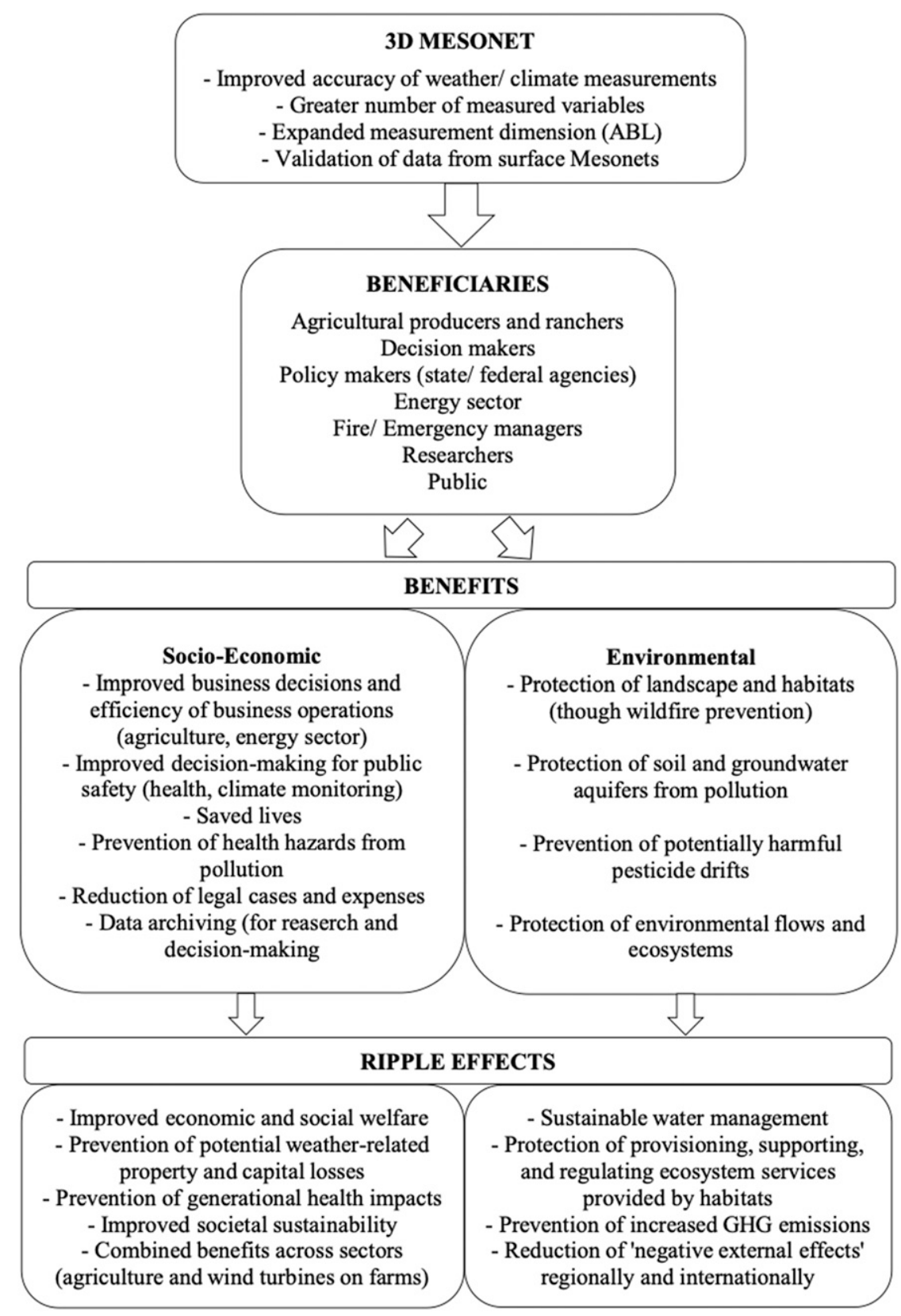

FIG. 4. Diagram of potential 3D mesonet beneficiaries, benefits, and ripple effects.

Even though the data resolution of WxUAS profile measurements will likely be lower compared to surface mesonets, the added vertical measurements can assist in improved weather forecasting and predictions and thus more effective decisionmaking with regard to initiation of convection or potential of unexpected and/or extreme weather events like tornadoes, icing, and fog. As these events often occur with little to no preparation time for decision-makers, the benefits of applying $3 \mathrm{D}$ mesonet data for improved weather forecasting and nowcasting can be characterized as short-term benefits, serving the affected citizens immediately or within a short time span. Notwithstanding, these short-term benefits have potential to prevent social long-term repercussions that could occur. More precisely, social losses can be avoided by reducing the number of human death cases by proper, more targeted, and timely preparations and evacuations on the ground. Because human life is invaluable, it is not possible to precisely estimate the social benefit provided by more accurate predictions achievable via a 3D mesonet. A cost-effectiveness analysis could possibly be applied as a valid approach to determine the extent of these impacts and changes, which would require more data and information about the practicality of the WxUAS technology application in this field, which does not exist at this time. 
Furthermore, economic losses can be prevented or reduced in reference to potential property damage from convective storms (e.g., unprotected vehicles, unsecured items in and around buildings, equipment used for construction or for industrial production). In effect, unwanted ripple effects can be avoided that would otherwise compromise household budgets, force people into poverty or homelessness, and disrupt businesses or put them out of operation, thus affecting human welfare and the economic welfare of the entire regional society. Changes in business operations would cause indirect effects via shifted or discontinued purchases in production materials and thus affect other production-related sectors. Similarly, these direct effects would most likely induce changes to social behaviors in the case of unemployment or changes in living standards of households and their family expenditures, thus affecting demand and supply for certain goods and services in other sectors of the economy.

Depending on the severity and acuteness of various weather events (e.g., tornadoes, icing, fog), the enumerated impacts would occur to different degrees during different seasons of the year, depending on the geographic location of the analyzed case. Accordingly, some economic impacts might occur only temporarily (e.g., discontinued business operation during an ice storm with short-term impacts), while others may lead to long-term business closures (e.g., severe tornado damage) that impact the business owner's family, the neighboring businesses, and economic sectors that supply the business with production factors such as materials or labor force.

Regardless of the degree of impact, it is unquestionable that more accurate predictions of high impact weather events and more precise nowcasting would benefit many societal groups and economic sectors. Broader socioeconomic impacts and benefits of a 3D mesonet could possibly be estimated with economic evaluation approaches, such as Input-Output analysis (Song et al. 2016; Yan et al. 2016), provided that information was available on the degree and scope of the measurement improvements taken by the WxUAS as compared with traditional surface mesonet data.

Environmental impacts of weather events relate mainly to changes in natural or anthropogenic ecosystems (e.g., damage to lakes, ponds, fish habitats, trees, and agricultural lands). While some ecosystem changes might be mostly harmless, others can cause ripple effects for economic sectors and societal activities. An environmental change of this kind could result in road rebuilding, which might cause social inconveniences (e.g., longer drive distances and higher travel costs) as well as other economic impacts on the siting of re-established businesses and delivery of production supplies.

\section{b. Agricultural sector}

The presence or absence of low-level inversions in the ABL are key to the safe and effective application of pesticides, herbicides, and fertilizers in large-scale agriculture operations (Thistle 2004). During an inversion, herbicides can remain suspended and injure nontargeted sensitive plants both on the same plantation plots as well as on neighboring plots, thus causing additional ripple effects. In 2017, the U.S. Environmental Protection Agency (EPA) noted over 2700 dicamba-related crop injury investigations across a 21-state region caused by off-field drift (EPA 2017). In addition, Bradley (2017, 2018) cataloged over 4000 dicamba-related investigations from state departments of agriculture in 2017 and 2018 alone.

Detecting and predicting local-scale inversion conditions is a great challenge requiring increased observations of the lowlevel ABL that a 3D mesonet could provide. Bish et al. (2019) found significant local variations in inversion formation time and duration at three Missouri farm locations they surveyed with in situ sensors placed on towers. Routine WxUAS profiles could provide real-time guidance for the agricultural community as well as build a climatology of conditions to aid agricultural planners. Such real-time observations could also improve frost and freeze warnings and mitigation response for growers. For instance, $\mathrm{Hu}$ et al. (2018) reviewed how air disturbance technology (e.g., tower-mounted wind machines) could offer significant frost protection over sensitive orchards during periods of inversions.

The benefits and ripple effects of WxUAS when applied in the agricultural sector are very pronounced and straightforward due to the many cases of unwanted drift of pesticides across the United States. The abovementioned case of dicamba (widely discussed by the EPA, policy makers, farmers, environmental stewards, and other stakeholders) is only one example of agricultural operations where a 3D mesonet could provide practical, far-reaching, broadly disseminated benefits geospatially and temporally. WxUAS technology has potential to support farmers' decision-making on planning the timing of pesticide application with the goal to optimize pinpoint application and avoid drifting that could cause (i) economic impacts (monetary losses to farmers as drifted herbicides would not protect the target plant and would force the farmers to reapply the herbicide), (ii) environmental impacts (injuring other crops and causing unnecessary double or triple amounts of pesticides injected into the environment through the reapplication), and (iii) social effects (impacting human health by exposure to harmful chemical drifts in the air with unknown health risks).

Through more effective application of pesticides/herbicides, which could be improved via 3D mesonet observations, a number of economic, environmental, and social positive effects could be achieved. From an economic standpoint, yields of agricultural production could be improved. Also, the measurements provided by the WxUAS technology (e.g., air temperature, relative humidity, and wind speed) could provide better assessment of evapotranspiration from plants, which would facilitate a more efficient irrigation strategy for the planted crops. Second, net returns of agricultural operations could be increased. The reapplication of additional pesticide doses causes new expenses and thus raises production costs for farmers, which can further lead to ripple effects for the consumers. Therefore, a negative economic impact of agricultural production due to ineffective pesticide application would generate a negative social ripple effect in the end, impacting the economics of consumer budgets and their families as a third-tier ripple effect. Another economic impact would be the prevention of lawsuits (e.g., those already noted with dicamba but also relevant to other engineered crops). Thus, ABL observations 
from a $3 \mathrm{D}$ mesonet could provide benefits by preventing legal cases and expenses for farmers.

In terms of environmental benefits, the unnecessary reapplication of additional pesticides doses could be avoided, thus protecting the environment, the natural habitats in the agricultural buffer zones, as well as the ecosystem services they provide. Destruction of ecosystem services on a large scale (both regionally and globally) has been discussed in the literature for many years, while the negative effects of these changes are very difficult to evaluate economically (Zanchi and Brady 2019; Kay et al. 2019; Briner et al. 2013). Lessening negative impacts of pesticide applications would also protect those humans and pollinators who naturally are a chain component of the Earth ecosystem. One example of a broader positive ripple effect that is worth mentioning relates to water bodies, especially aquifers underneath agricultural fields. Through improved pesticide applications, scarce water resources could be protected, especially in regions with heavy agricultural production relying on underground aquifers. Thus, environmental pressures in water availability could be lessened, as these resources are already compromised by recurring droughts. Furthermore, the availability of water as a production factor would divert farmers from searching for new, more expensive water sources.

For societal benefits, human health could be protected by preventing exposure to harmful chemical drifts, both with the first drift and any resulting drift of pesticide reapplication. It has been documented in the health sciences that pesticides can cause health reactions in humans (Sengupta and Banerjee 2014; Curl et al. 2002). While farmers' families have primary exposure to this risk, the drifts have larger-scale impacts, affecting neighboring regions. Moreover, excessive application of pesticides (and their absorption in crops) can cause allergies and compromise the human immune system (Mokarizadeh et al. 2015). The human uneasiness and distrust in application of chemicals causes another behavioral issue, which, while relevant in the discussions of this topic, is very difficult to quantify in economic terms.

Both for the environmental and societal impacts, a situation of "negative external effects" could emerge. These effects, also referred in economic terms as "external costs," are negative impacts of human actions and behaviors that are not recompensed by the damaging party, but borne by the affected party, thus causing unwanted environmental and social ripple effects. For instance, diseases and allergies resulting from excessive or inefficient pesticide applications increase the number of persons seeking medical help, increasing medical bills for affected citizens, while also potentially straining the medical system, as a part of the country's economic sector. This example represents several ripple effects on the social and economic level both for individuals and economic sectors at large.

Last, we note that the negative effects of pesticide drifts and their socioeconomic and environmental impacts create a cumulative effect and could have generational impacts on these three levels, thus impacting the sustainability of agricultural production and the sector. Enhanced observations from a 3D mesonet as a new technological innovation could lessen the vicious cycle of ineffective pesticide applications, and thus benefit agricultural production, operations, the environment, employees in this sector, and citizens in the region.

\section{c. Wildland fire management}

Wildland fire is heavily influenced by meteorological conditions. Knowledge of the temperature, wind, and relative humidity can allow for predictions of the likelihood of fire initiation (e.g., dry, warm fuels are more likely to ignite). Additionally, observations of the surface and boundary layer profiles of temperature, wind, and relative humidity can indicate how a resulting fire and associated smoke will spread and disperse (San-Miguesl-Ayanz et al. 2003). The low-level wind field is generally responsible for the propagation behavior of fire. With the potential addition of low-level temperature and wind profiles provided by a 3D mesonet, a greater understanding and prediction of smoke dispersal could be provided. Similar to agricultural applications described above, temperature inversions (i.e., conditions where temperatures increase with height) inhibit mixing and lead to poor visibility and high contaminant concentrations (Goodrick et al. 2013; see also Fig. 5). Liu et al. (2019) reviewed the important needs for smoke forecasting via the coupling of fire, smoke, and atmospheric processes. Nelson et al. (2019) developed an instrument package for deployment on WxUAS to measure air temperature, humidity, pressure, particulate matter, carbon monoxide, and carbon dioxide. Their system was flown over several prescribed fires and had promising results in characterizing gas and meteorological conditions within and adjacent to fire areas.

Recent research has found that observations of low-level temperature profiles alone can provide valuable insight into the likelihood of fire outbreaks. Lindley et al. (2017) found that thermal ridges in the lowest levels of the atmosphere enhance wildland fire activity on the southern Great Plains. These low-level thermal ridges are characterized by anomalously warm and dry air that provides strong boundary layer mixing conducive for fire. WxUAS measurements of the ABL show great promise for advancing the prediction of wildland fires, which would generate socioeconomic and environmental benefits both for the regions of the fire outbreaks as well as adjacent regions. As shown in Fig. 5, the resulting smoke might disperse over long distances, creating a potential risk for many communities.

For regions affected directly by wildland fire, 3D mesonet observations have the potential to prevent unnecessary economic losses to different societal groups and to protect natural environments, ecosystems, and habitats. Economic benefits can be directly recognized when one considers the acreage of burned lands. One pertinent example was presented by Ziolkowska (2019) who analyzed socioeconomic effects of the Rhea megafire in Oklahoma during the spring of 2018, which caused 286742 acres $(1$ acre $=0.4$ ha) to burn. Ziolkowska estimated the direct, indirect, induced, and spillover effects of this single fire event to amount to $\$ 54$ million, which included land losses (and related property value), animal husbandry losses, land rent losses (for cropland, pastures, hay), lost market value of products sold (as direct economic effects), value of agricultural services (rentals of machinery), Commodity Credit 
(a) low intensity, stable atmosphere

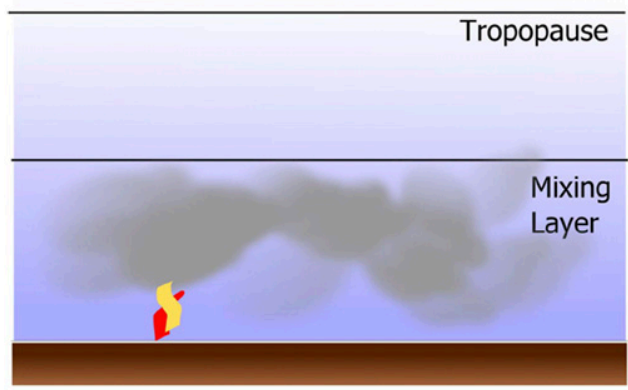

(c) moderate intensity, well-mixed atmosphere

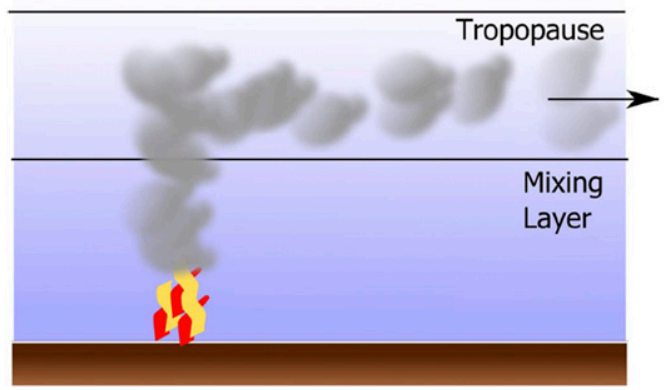

(b) low intensity, well-mixed atmosphere

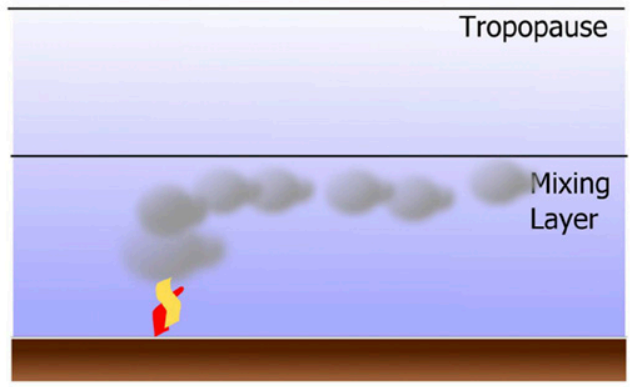

(d) high intensity, unstable atmosphere

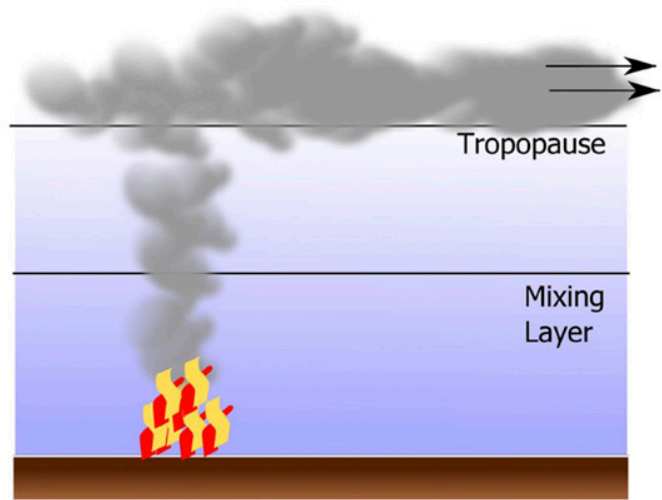

FIG. 5. Typical smoke dispersion scenarios, given differing atmospheric conditions. (a) During stable conditions, smoke stays close to the ground, while (d) during unstable conditions, smoke disperses high into the atmosphere (reprinted from Williamson et al. 2016).

Corporation loans for agricultural producers, operating expenses of farming activities (including indirect economic effects from feed, fertilizer, fuel, building expenses), losses of funds provided through government programs to agricultural producers, income losses (due to lost land), and spillover effects of increases in unemployment of contractual and hired labor workers. Consequently, induced economic effects could be derived with regard to changes in human behaviors due to compromised incomes or employment, further impacting other sectors of the regional economy.

While the monetary value of benefits provided through the application of a 3D mesonet cannot be estimated precisely at this time due to limited statistics, it is apparent that improved prediction accuracy of fire events could provide significant economic benefits by preventing unexpected fires or improving fire management and control in a more effective way. However, scenarios could be modeled to determine economic gains of prevented losses due to fire events by the application of $3 \mathrm{D}$ mesonet. The derived value would accordingly correspond to the degree and scope of additional measurements provided by WxUAS technology as compared with traditional surface observations.

Environmental benefits of a 3D mesonet through more effective prediction and monitoring of fires is primarily achieved through prevention of land/property losses. While these losses are typically evaluated from an economic perspective, the ecosystem value of lost habitats in a fire event cannot be overlooked, as these habitats normally would take many years to be restored naturally. High contaminant concentration caused by fires can affect both the fauna and flora, as well as human beings, thus causing direct social repercussions.

In more extreme cases, wildfires can be a cause of hazardous chemical exposure due to fume release from burning oil, chemicals, fertilizers, and pesticides if storage facilities are affected. Environmental and social impacts could include an outbreak of acute health situations, and thus affect the medical sector of the economy and increase medical expenses of affected individuals. Oftentimes, there is no clearly identifiable injuring party in a case of a wildfire event, and thus the external costs cannot be recompensed to the injured parties. As one example of a ripple effect, wildfires could also impact public buildings (e.g., schools and agencies), which could potentially result in increased taxes for the public.

Understanding the broader picture of potential negative impacts on regional, national, and international societies on the one hand, and the benefits of a 3D mesonet to prevent these damages on the other, clearly proves the need to explore possibilities of implementing WxUAS in this new application area.

\section{d. Public health and air quality}

Although air quality in the United States has improved steadily since the passage of the Clean Air Act in the 1970s, 
137 million Americans still live in areas where one or more National Ambient Air Quality Standards (NAAQS) are in nonattainment as of 2019 (EPA 2019). While improved rates of attainment may be achieved through technological advances in green manufacturing, industrial practices, or targeted regulations, it is important to understand how meteorological conditions may play a role in exacerbating or abating underlying pollution issues on a local or regional scale. Low-level inversions are often correlated with extreme air quality events, such as the Donora Smog of 1948 and the Great London Fog of 1952, because stagnant air masses prevent emissions of carbon monoxide, nitric oxide, nitrogen dioxide, sulfur dioxide, and particulate matter from escaping the surface layer (Jacobs et al. 2018; Wang et al. 2016). While the wind fields in the ABL dictate the dispersion of pollutants (Carlson and Arndt 2008), the $3 \mathrm{D}$ thermodynamic structure determine the height to which pollutants will mix. This relationship between emissions, meteorological variability, and chemical dynamics that results in short-term fluctuations in atmospheric chemical composition is called chemical weather and is a current area of focus in atmospheric chemistry research (Lawrence et al. 2005). For example, humidity can significantly impact the composition and acidity of aerosols in haze and smog. Nitric oxide and nitrogen dioxide react with volatile organics in the gas phase to produce organic nitrates that partition to the particle phase and undergo hydrolysis to produce nitrate (Vasquez et al. 2020). These reactions lower the $\mathrm{pH}$ of cloud droplets (Tao et al. 2020) and thus promote acid rain.

Studies have shown there is a correlation between elevated $\mathrm{PM}_{2.5}$ pollution and decreasing boundary layer heights as well atmospheric circulation patterns that promote stagnation and recirculation of air masses (Miao et al. 2018; Zhao et al. 2019). Dry, tropical air masses and stagnation events during the summer have led to ozone nonattainment events throughout the Midwest (Jing et al. 2017) and field campaigns like the Lake Michigan Ozone Study (LMOS) and the Ozone Water-Land Environmental Transition Study (OWLETS) have highlighted how nonattainment along coastal areas can be driven by lakeand sea-breeze circulations that bring ozone-rich air inland from shallow pollution rich layers over the water (AbdiOskouei et al. 2019; Dye et al. 1995; Sullivan et al. 2019). These challenges at the interface between meteorology and atmospheric chemistry point to a critical need for new instrumentation and methods to study the dynamics of chemical weather.

Improved air quality forecasts will require more data on the spatiotemporal evolution of the thermodynamics, kinematics, and chemical composition of the ABL. WxUAS profiles deployed in and around urban centers could provide these data with some units being equipped with additional gas and particulate sensors.

Since atmospheric chemistry variables are not measured by traditional surface mesonet stations, this new data type offered by WxUAS unquestionably could provide added-value benefits of the $3 \mathrm{D}$ mesonet. Due to the high variability of atmospheric phenomena occurring in the ABL, the measurements of chemical components would allow for a better understanding of how the structure of the ABL leads to different types of air quality events and potential air quality concerns.
Additionally, the new measurements could lead to improved decision-making processes by health professionals and advisors about potential air pollution exposure risks, air pollution hazards, and necessary precautions to be taken by citizens in affected regions.

Air pollution can be a cause of multiple socioeconomic and environmental hazards, which could be aggravated by its rapidly changing and unpredictable occurrence. The most concerning impacts relate to short- and long-term social sustainability of societies (e.g., health-related well-being), which can result in both short- and long-term economic and generational ripple effects at large, accordingly.

Regardless of the duration of pollution events and the related exposure to potentially harmful substances, direct economic impacts for citizens can manifest in increased individual medical expenses (i.e., due to negative external effects of pollution), further impacting household expenditures. In the case of a prolonged pollution exposure, the cumulative effect of compromised health conditions in individuals could lead to compounded long-term health issues such as ischemic heart disease, stroke, and chronic obstructive pulmonary disease (COPD), which could lead to lifelong medical medication or treatment (Hadei et al. 2017; Lo et al. 2017). Those individuals with compromised immune systems would be most vulnerable, including the elderly and children, thus potentially instigating generational societal ripple effects.

Additionally, in cases of both occasional air pollution conditions and prolonged pollution, societal and economic activities might be disrupted causing businesses to close operation, diverting workers from work, preventing citizens from leaving homes, and thus limiting the financial flow in the economy, especially in the area of services (i.e., induced effects of changed individual behaviors in the society). Depending on the affected region, air pollution might cause indirect impacts on other economic sectors. The agricultural sector might experience harmful chemicals that infiltrate the soil and groundwater resources via rain, thus affecting crops and potentially creating another source of health hazard when harmful chemicals are consumed with produce. While soil and groundwater contamination by air pollution could prove to be most impactful for agricultural production, it could also affect the environment at large (e.g., biota, ecosystems, and ecosystem services freely available through the natural environment to the society). While environmental and economic impacts of air pollution on ecosystems have been widely analyzed in different countries around the globe (De Carvalho and Szlafsztein 2019; De Marco et al. 2019; Ochoa-Hueso et al. 2017), their degree and impacts depend on the geographic location, exposure to the harmful chemicals, concentration of the chemicals in the air, the speed of their release into the environment, and the frequency of pollution events in a given region. Thus, these impacts (and economic benefits of applying data from a 3D mesonet for better prediction, monitoring, and decisionmaking) can likely only be assessed monetarily case by case for each pollution event.

The meteorological and chemical data collected with WxUAS could also be used to improve air quality models. Air quality models are used to inform the public of future poor air quality 
events so that susceptible populations can change their behavior accordingly. As outlined in section 4a, routine profiling with WxUAS can be harnessed to improve the initialization of models, such as the coupled WRF-Chemistry Model (WRF-Chem) and WRF-Vegetation Photosynthesis and Respiration Model (WRF-VPRM), which have historically struggled to correctly model the concentrations of gases and particulates in the ABL (Abdi-Oskouei et al. 2020; Hu et al. 2020). More accurate air quality forecasts could result in fewer air quality related illnesses, particularly from fewer missed poor air quality events. There is also a benefit to be gained with fewer false alarm events. In turn, the improved guidance from these models could shape policies at the federal, state, and local level to include more effective pollution control strategies that will benefit public health outcomes.

While health and medical expenses in societies are a public data source, it is almost impossible to pinpoint and validate scientifically the exact health cases attributed to air pollution. This is especially the case when health issues in individuals develop over time due to the accumulation of air pollutants (e.g., asthma in children). Thus, determining socioeconomic and environmental benefits of a 3D mesonet in monetary terms is too complex at this time. However, these benefits could be evaluated for a specific societal group in a given region when operational WxUAS data become available.

\section{e. Wind energy}

Understanding the characteristics of the ABL at a given location is essential for assessing wind energy potential. Historically, such observations were made with tall, portable 60-100-m towers or via remote sensing instruments (i.e., sodars and lidar). In the coming decade, wind turbines are projected to reach heights in excess of $140 \mathrm{~m}$, making measurements via portable towers less practical. In a similar manner, observations derived from sodars and lidars have their own limitations. For example, sodar and lidar measurements are both quite costly and are compromised when precipitation is occurring. Additionally, sodar measurements can be biased by acoustic noise while lidar measurements require adequate concentrations of aerosols in the atmosphere. The use of WxUAS to regularly sample profiles of the ABL could be an inexpensive and flexible option for providing needed measurements for the wind industry. In addition to wind speed information, a 3D mesonet could provide observations of temperature, relative humidity, and pressure to infer static stability, another parameter strongly correlated with wind power output (Wharton and Lundquist 2010).

The most outstanding economic benefit of WxUAS in the wind energy sector relates to gaining a better understanding of wind shifts and turbulences at taller wind turbine heights. This improved knowledge could have direct impacts on decisions with regard to the location selection for new wind farms to make wind energy harvesting most efficient, and thus improving the economics and net returns of the business operation both for the wind producing company and the final consumer. Smaller down payments and lower building costs of wind farms would translate to lower consumer prices for wind energy. Furthermore, optimally siting wind farms allows for the highest possible efficiency in wind energy gains, and at the same time, improves daily operational costs of wind turbines. Because wind characteristics in the ABL change seasonally, the flexibility of WxUAS technology could be useful to regularly monitor these changes, and thus provide scientific background for informed decision-making both for the energy sector, stakeholders, and governmental entities issuing permits for turbine locations. A proper site selection would ensure the longevity of the investment and result in optimized economic gains and possible economies of scale over the long term.

The application of a 3D mesonet in the wind energy sector could show even more pronounced benefits and ripple effects if applied at wind turbines located in agricultural areas. Many farmers enter mutual agreements with wind power producers to allow wind turbines to be placed on their farmlands with lower soil quality or on marginal or abandoned land sections, thus utilizing the space not usable otherwise for crop planting or animal grazing. Thus, the same WxUAS technology could be applied both for wind energy purposes and farming purposes (as described in the previous section) at that same location, thus generating cumulative and compounded benefits for farmers. Also, studies have shown that sodars and lidars have already been supplanted with UAS to reduce the cost of data collection (Nagy and Jahn 2019).

Optimizing turbine location for maximum operational efficiency could generate positive social benefits as well by dissipating societal uneasiness about wind turbines, their aesthetics, noise, and potential negative environmental impacts, as analyzed by some studies on local bird and bat habitats (Everaert and Stienen 2006; Miao et al. 2019; Aschwanden et al. 2018; Barré et al. 2018). Additionally, measuring and archiving new datasets of the ABL could facilitate the creation of a database for the wind industry for long-term projections.

Renewables are becoming an important source of energy generation in almost every country as a means to ensure energy sustainability and reliability. Therefore, new technologies like WxUAS enhance the development of the wind energy sector, creating long-term generational benefits for regional economies. In this way, an energy portfolio could be extended, even though intermittent at times, in the quest of energy diversification needs for greater stability and independency of the national energy sector.

\section{f. Climate monitoring}

Global climate monitoring has historically focused on changes in temperature at the 1.5-2.0-m level. Lin et al. (2015) noted that "knowledge of near-surface temperature trends with respect to height, however, is limited and inadequately understood because surface temperature observations at different heights in the surface layer of the world are rare especially from a high-quality and long-term climate monitoring network." With their analysis of mesonet temperature data at 1.5 and $9.0 \mathrm{~m}$ over the period between 1997 and 2003, the authors found statistically significant changes observed in temperature lapse rates in the lowest $9 \mathrm{~m}$, despite the fact that no trends were detected in the individual height data. Thus, the addition of long-term monitoring of temperature profiles via a $3 \mathrm{D}$ mesonet could possibly reveal changes occurring in lapse 
rates that are impossible to detect with traditional surface data alone.

One of the direct social benefits of WxUAS measurements in climate monitoring is improved knowledge of long-term weather changes over time. A more precise and routine tracking of temperature, humidity, wind speed, and carbon dioxide changes would allow for building reliable archives on weather and chemistry changes in the ABL.

As mentioned previously, because of its rarity in measurements, data archives of this kind would generate an important added value for researchers and decision-makers both in the regions of application, nationally, and internationally benefiting organizations in analyzing, mitigating, and adapting to climate changes. As proven by traditional surface mesonet data, viable examples and applications from one region often spread quickly to other regions. Thus, a $3 \mathrm{D}$ mesonet, as soon as proven for its practical application in the new areas discussed in this paper, could possibly be sought to be applied in other regions of the world, thus generating wide-scale benefits. Moreover, precise databases generate a reliable research resource for universities and research institutes, thus facilitating the creation of new intellectual property resulting in new patents, publications, research projects, and support for student and postdoctoral researchers. These developments have direct societal benefits through the added value of increased knowledge (which can be referred to as a "positive external effect" to society).

\section{Summary}

Many advancements have been made in recent years with regard to research and development of WxUAS. Highresolution profiles of the $\mathrm{ABL}$ have already provided unique insight into the structure and evolution of this undersampled portion of the atmosphere. While the operation and application of WxUAS technology in mesonets are still in their early stages, there exists great potential for socioeconomic and environmental benefits of wide-scale deployments. In this paper, we have explored direct, indirect, induced, and ripple effects on six sectors, focusing on practical applications. Our discussions targeted qualitative assessments at this time, but we feel this first step is necessary for laying the groundwork for future quantitative studies.

Acknowledgments. This work was made possible through funding from the National Mesonet Program and the Office for the Vice President for Research at the University of Oklahoma.

\section{REFERENCES}

Abdi-Oskouei, M., andCoauthors, 2019: 2017 Lake Michigan Ozone Study (LMOS). LADCO Preliminary Finding Rep., 105 pp., https://www.ladco.org/wp-content/uploads/Research/ LMOS2017/LMOS_LADCO_report_revision_apr2019_final.pdf.

_ , andCoauthors, 2020: Sensitivity of meteorological skill to selection of WRF-Chem physical parameterizations and impact on ozone prediction during the Lake Michigan Ozone Study (LMOS). J. Geophys. Res. Atmos., 125, e2019JD031971, https://doi.org/10.1029/2019JD031971.
Ahlawat, A., S. K. Mishra, S. Gumber, V. Goel, C. Sharma, and A. Wiedensohler, 2019: Performance evaluation of light weight gas sensor system suitable for airborne applications against colocation gas analysers over Delhi. Sci. Total Environ., 697, 134016, https://doi.org/10.1016/j.scitotenv.2019.134016.

Alvarado, M., F. Gonzalez, P. Erskine, D. Cliff, and D. Heuff, 2017: A methodology to monitor airborne PM10 dust particles using a small unmanned aerial vehicle. Sensors, 17, 343, https:// doi.org/10.3390/s17020343.

American Meteorological Society, 2020: Mesoscale. Glossary of Meteorology, http://glossary.ametsoc.org/wiki/mesoscale.

Aschwanden, J., H. Stark, D. Peter, T. Steuri, B. Schmid, and F. Liechti, 2018: Bird collisions at wind turbines in a mountainous area related to bird movement intensities measured by radar. Biol. Conserv., 220, 228-236, https://doi.org/10.1016/ j.biocon.2018.01.005.

Aweiss, A. S., B. D. Owens, J. Rios, J. R. Homola, and C. P. Mohlenbrink, 2018: Unmanned Aircraft Systems (UAS) Traffic Management (UTM) National Campaign II. AIAA SciTech Forum, Kissimmee, FL, American Institute of Aeronautics and Astronautics, 1727, https://doi.org/10.2514/6.2018-1727.

Barré, K., I. Viol, Y. Bas, R. Julliard, and C. Kerbiriou, 2018: Estimating habitat loss due to wind turbine avoidance by bats: Implications for European siting guidance. Biol. Conserv., 226, 205-214, https://doi.org/10.1016/j.biocon.2018.07.011.

Båserud, L., J. Reuder, M. O. Jonassen, T. A. Bonin, P. B. Chilson, M. A. Jiménez, and P. Durand, 2020: Potential and limitations in estimating sensible-heat-flux profiles from consecutive temperature profiles using remotely-piloted aircraft systems. Bound.-Layer Meteor., 174, 145-177, https://doi.org/10.1007/ s10546-019-00478-9.

Bell, T. M., B. R. Greene, P. M. Klein, M. Carney, and P. B. Chilson, 2020: Confronting the boundary layer data gap: Evaluating new and existing methodologies of probing the lower atmosphere. Atmos. Meas. Tech., 13, 3855-3872, https:// doi.org/10.5194/amt-13-3855-2020.

Bish, M. D., P. E. Guinan, and K. W. Bradley, 2019: Inversion climatology in high-production agricultural regions of Missouri and implications for pesticide applications. J. Appl. Meteor. Climatol., 58, 1973-1992, https://doi.org/10.1175/JAMC-D-180264.1.

Bonin, T., P. Chilson, B. Zielke, and E. Fedorovich, 2013: Observations of the early evening boundary-layer transitions using a small unmanned aerial system. Bound.-Layer Meteor., 146, 119-132, https://doi.org/10.1007/s10546-012-9760-3.

Bradley, K. W., 2017: A final report on dicamba-injured soybean acres. Integrated Pest and Crop Management Newsletter, University of Missouri, https://ipm.missouri.edu/IPCM/2017/ 10/final_report_dicamba_injured_soybean/.

__, 2018: July 15 dicamba injury update. Different year, same questions. Integrated Pest and Crop Management Newsletter, University of Missouri, https://ipm.missouri.edu/IPCM/2018/ 7/July-15-Dicamba-injury-update-different-year-same-questions/.

Brady, J. M., M. D. Stokes, J. Bonnardel, and T. H. Bertram, 2016: Characterization of a quadrotor unmanned aircraft system for aerosol-particle-concentration measurements. Environ. Sci. Technol., 50, 1376-1383, https://doi.org/10.1021/acs.est.5b05320.

Briner, S., C. Elkin, and R. Huber, 2013: Evaluating the relative impact of climate and economic changes on forest and agricultural ecosystem services in mountain regions. J. Environ. Manage., 129, 414-422, https://doi.org/10.1016/j.jenvman.2013.07.018.

Brosy, C., K. Krampf, M. Zeeman, B. Wolf, W. Junkermann, K. Schäfer, S. Emeis, and H. Kunstmann, 2017: Simultaneous 
multicopter-based air sampling and sensing of meteorological variables. Atmos. Meas. Tech., 10, 2773-2784, https://doi.org/ 10.5194/amt-10-2773-2017.

Brotzge, J. A., and Coauthors, 2018: Development of a statewide, multiuse surface and vertical profiling network: An overview of the New York State Mesonet. 22nd Conf. on Integrated Observing and Assimilation Systems for the Atmosphere, Oceans, and Land Surface, Austin, TX, Amer. Meteor. Soc., 7.6, https:// ams.confex.com/ams/98Annual/webprogram/Paper333289.html.

Carbone, R. E., and Coauthors, 2012: Thermodynamic Profiling Technologies Workshop Report to the National Science Foundation and the National Weather Service. NCAR Tech. Rep. NCAR/TN-488+STR, 80 pp., https://doi.org/10.5065/ D6SQ8XCF.

Carlson, J. D., and D. S. Arndt, 2008: The Oklahoma Dispersion Model: Using the Gaussian plume model as an operational management tool for determining near-surface dispersion conditions across Oklahoma. J. Appl. Meteor. Climatol., 47, 462-474, https://doi.org/10.1175/2007JAMC1418.1.

Chilson, P. B., and Coauthors, 2019: Moving towards a network of autonomous UAS atmospheric profiling stations for observations in the Earth's lower atmosphere: The 3D mesonet concept. Sensors, 19, 2720, https://doi.org/10.3390/s19122720.

Cione, J. J., and Coauthors, 2020: Eye of the storm: Observing hurricanes with a small unmanned aircraft system. Bull. Amer. Meteor. Soc., 101, E186-E205, https://doi.org/10.1175/BAMSD-19-0169.1.

Crowe, W., and Coauthors, 2012: Enabling science use of unmanned aircraft systems for Arctic environmental monitoring. Arctic Monitoring and Assessment Programme Tech. Rep. 6, 30 pp.

Curl, C. L., R. A. Fenske, J. C. Kissel, J. H. Shirai, T. F. Moate, W. Griffith, G. Coronado, and B. Thompson, 2002: Evaluation of take-home organophosphorus pesticide exposure among agricultural workers and their children. Environ. Health Perspect., 110, 787-792, https://doi.org/10.1289/ehp.021100787.

de Boer, G., B. Argrow, J. Cassano, J. Cione, E. Frew, D. Lawrence, G. Wick, and C. Wolff, 2019: Advancing unmanned aerial capabilities for atmospheric research. Bull. Amer. Meteor. Soc., 100, ES105-ES108, https://doi.org/10.1175/BAMS-D-18-0254.1.

De Carvalho, R. M., and C. F. Szlafsztein, 2019: Urban vegetation loss and ecosystem services: The influence on climate regulation and noise and air pollution. Environ. Pollut., 245, 844852, https://doi.org/10.1016/j.envpol.2018.10.114.

De Marco, A., and Coauthors, 2019: Impacts of air pollution on human and ecosystem health, and implications for the National Emission Ceilings Directive: Insights from Italy. Environ. Int., 125, 320-333, https://doi.org/10.1016/j.envint.2019.01.064.

Durre, I., R. S. Vose, and D. B. Wuertz, 2006: Overview of the integrated global radiosonde archive. J. Climate, 19, 53-68, https://doi.org/10.1175/JCLI3594.1.

Dye, T. S., P. T. Roberts, and M. E. Korc, 1995: Observations of transport processes for ozone and ozone precursors during the 1991 Lake Michigan Ozone Study. J. Appl. Meteor., 34, 1877-1889, https://doi.org/10.1175/1520-0450(1995)034<1877: OOTPFO $>2.0 . \mathrm{CO} ; 2$.

Elston, J., B. Argrow, M. Stachura, D. Weibel, D. Lawrence, and D. Pope, 2015: Overview of small fixed-wing unmanned aircraft for meteorological sampling. J. Atmos. Oceanic Technol., 32, 97-115, https://doi.org/10.1175/JTECH-D-13-00236.1.

EPA, 2017: Dicamba/auxin formulations. PowerPoint presentation, accessed 1 October 2019, https://www.epa.gov/sites/ production/files/2017-11/documents/ppdc-dicamba-overviewupdate-nov-1-2017.pdf.
_, 2019: Our nation's air. Accessed 4 June 2020, https:// gispub.epa.gov/air/trendsreport/2019/\#home.

Everaert, J., and E. Stienen, 2006: Impact of wind turbines on birds in Zeebrugge (Belgium). Biodiversity and Conservation in Europe, A. T. Bull and D. L. Hawksworth, Eds., Springer, 103-117.

Fiebrich, C. A., and Coauthors, 2020: Toward the standardization of mesoscale meteorological networks. J. Atmos. Oceanic Technol., 37, 2033-2049, https://doi.org/10.1175/JTECHD-20-0078.1.

Glasheen, K., J. Pinto, M. Steiner, and E. Frew, 2019: Experimental assessment of local weather forecasts for small unmanned aircraft flight. Scitech 2019 Forum, Reston, VA, American Institute of Aeronautics and Astronautics, AIAA 2019-1193, https://doi.org/10.2514/6.2019-1193.

Goodrick, S. L., G. L. Achtemeier, N. K. Larkin, Y. Liu, and T. M. Strand, 2013: Modelling smoke transport from wildland fires: A review. Int. J. Wildland Fire, 22, 83-94, https://doi.org/ 10.1071/WF11116.

Greene, B. R., A. R. Segales, S. Waugh, S. Duthoit, and P. B. Chilson, 2018: Considerations for temperature sensor placement on rotary-wing unmanned aircraft systems. Atmos. Meas. Tech., 11, 5519-5530, https://doi.org/10.5194/amt-11-5519-2018. , — , T. M. Bell, E. A. Pillar-Little, and P. B. Chilson, 2019: Environmental and sensor integration influences on temperature measurements by rotary-wing unmanned aircraft systems. Sensors, 19, 1470, https://doi.org/10.3390/ s19061470.

Hadei, M., S. S. Hashemi Nazari, A. Eslami, A. Khosravi, M. Yarahmadi, Z. Naghdali, and A. Shahsavani, 2017: Distribution and number of ischemic heart disease (IHD) and stroke deaths due to chronic exposure to $\mathrm{PM}_{2.5}$ in 10 cities of Iran (2013-2015); an AIRQ + modelling. J. Air Pollut. Health, 2, 129-136.

Hemingway, B. L., A. E. Frazier, B. R. Elbing, and J. D. Jacob, 2017: Vertical sampling scales for atmospheric boundary layer measurements from small unmanned aircraft systems (sUAS). Atmosphere, 8, 176, https://doi.org/10.3390/atmos8090176.

Hocker, J. E., A. D. Melvin, K. A. Kloesel, C. A. Fiebrich, R. W. Hill, R. D. Smith, and S. F. Piltz, 2018: The evolution and impact of a meteorological outreach program for public safety officials: An update on the Oklahoma Mesonet's OK-First program. Bull. Amer. Meteor. Soc., 99, 2009-2024, https:// doi.org/10.1175/BAMS-D-17-0100.1.

Houston, A., B. Argrow, J. Elston, J. Lahowetz, and P. Kennedy, 2012: The Collaborative Colorado-Nebraska Unmanned Aircraft System Experiment. Bull. Amer. Meteor. Soc., 93, 3954, https://doi.org/10.1175/2011BAMS3073.1.

$\mathrm{Hu}, \mathrm{X}$.-M., and Coauthors, 2020: Dynamical downscaling of $\mathrm{CO}_{2}$ in 2016 over the contiguous United States using WRF-VPRM, a weatherbiosphere-online-coupled model. J. Adv. Model. Earth Syst., 12, e2019MS001875, https://doi.org/10.1029/2019MS001875.

Hu, Y., E. A. Asante, Y. Lu, A. Mahmood, N. A. Buttar, and S. Yuan, 2018: Review of air disturbance technology for plant frost protection. Int. J. Agric. Biol. Eng., 11, 21-28, https:// doi.org/10.25165/j.ijabe.20181103.3172.

Jacobs, E. T., J. L. Burgess, and M. B. Abbott, 2018: The Donora Smog revisited: 70 years after the event that inspired the Clean Air Act. Amer. J. Public Health, 108, S85-S88, https://doi.org/ 10.2105/AJPH.2017.304219.

Jing, P., Z. Liu, and A. L. Steiner, 2017: The ozone-climate penalty in the Midwestern U.S. Atmos. Environ., 170, 130-142, https:// doi.org/10.1016/j.atmosenv.2017.09.038. 
Kay, S., and Coauthors, 2019: Agroforestry is paying off-Economic evaluation of ecosystem services in European landscapes with and without agroforestry systems. Ecosyst. Serv., 36, 100896, https://doi.org/10.1016/j.ecoser.2019.100896.

Koch, S. E., M. Fengler, P. B. Chilson, K. L. Elmore, B. Argrow, D. L. Andra Jr., and T. Lindley, 2018: On the use of unmanned aircraft for sampling mesoscale phenomena in the preconvective boundary layer. J. Atmos. Oceanic Technol., 35, 2265-2288, https://doi.org/10.1175/JTECH-D-18-0101.1.

Kunz, M., and Coauthors, 2018: COCAP: A carbon dioxide analyser for small unmanned aircraft systems. Atmos. Meas. Tech. Discuss., 11, 1833-1849, https://doi.org/10.5194/amt-11-18332018.

Lawrence, M. G., Ø. Hov, M. Beekmann, J. Brandt, H. Elbern, H. Eskes, H. Feichter, and M. Takigawa, 2005: The chemical weather. Environ. Chem., 2, 6-8, https://doi.org/10.1071/EN05014.

Lazo, J. K., M. Lawson, P. H. Larsen, and D. M. Waldman, 2011: U.S. economic sensitivity to weather variability. Bull. Amer. Meteor. Soc., 92, 709-720, https://doi.org/10.1175/ 2011BAMS2928.1.

Lee, T. R., M. Buban, E. Dumas, and C. B. Baker, 2017: A new technique to estimate sensible heat fluxes around micrometeorological towers using small unmanned aircraft systems. J. Atmos. Oceanic Technol., 34, 2103-2112, https://doi.org/ 10.1175/JTECH-D-17-0065.1.

Leuenberger, D., A. Haefele, N. Omanovic, M. Fengler, G. Martucci, B. Calpini, O. Fuhrer, and A. Rossa, 2020: Improving high-impact numerical weather prediction with lidar and drone observations. Bull. Amer. Meteor. Soc., 101, E1036-E1051, https://oi.org/ 10.1175/BAMS-D-19-0119.1.

Lin, X., R. A. Pielke Sr. R. Mahmood, C. A. Fiebrich, and R. Aiken, 2015: Observational evidence of temperature trends at two levels in the surface layer. Atmos. Chem. Phys. Discuss., 15, 24 695-24 726, https://doi.org/10.5194/acpd-15-24695-2015.

Lindley, T. T., B. R. Bowers, G. P. Murdoch, B. R. Smith, and C. M. Gitro, 2017: Analyses of fire-effective low-level thermal ridges on the southern Great Plains. J. Oper. Meteor., 05, 146-160, https://doi.org/10.15191/nwajom.2017.0512.

Liu, Y., and Coauthors, 2019: Fire behaviour and smoke modelling: Model improvement and measurement needs for next-generation smoke research and forecasting systems. Int. J. Wildland Fire, 28, 570-588, https://doi.org/10.1071/WF18204.

Lo, W. C., R. H. Shie, C. C. C. Han, and H. H. Lin, 2017: Burden of disease attributable to ambient fine particulate matter exposure in Taiwan. J. Formosan Med. Assoc., 116, 32-40, https:// doi.org/10.1016/j.jfma.2015.12.007.

Lothon, M., and Coauthors, 2014: The BLLAST field experiment: Boundary-Layer Late Afternoon and Sunset Turbulence. Atmos. Chem. Phys. Discuss., 14, 10 789-10 852, https://doi.org/10.5194/ acp-14-10931-2014.

Mahmood, R., and Coauthors, 2017: Mesonets: Mesoscale weather and climate observations for the United States. Bull. Amer. Meteor. Soc., 98, 1349-1361, https://doi.org/10.1175/BAMS-D15-00258.1.

Mayer, S., A. Sandvik, M. O. Jonassen, and J. Reuder, 2012: Atmospheric profiling with the UAS SUMO: A new perspective for the evaluation of fine-scale atmospheric models. Meteor. Atmos. Phys., 116, 15-26, https://doi.org/10.1007/ s00703-010-0063-2.

McFarquhar, G. M., and Coauthors, 2020: Current and future uses of UAS for improved forecasts/warnings and scientific studies. Bull. Amer. Meteor. Soc., 101, E1322-E1328, https://doi.org/ 10.1175/BAMS-D-20-0015.1.
Miao, R., P. N. Ghosh, M. Khanna, W. Wang, and J. Rong, 2019: Effect of wind turbines on bird abundance: A national scale analysis based on fixed effects models. Energy Policy, 132, 357-366, https://doi.org/10.1016/j.enpol.2019.04.040.

Miao, Y., S. Liu, J. Guo, S. Huang, Y. Yan, and M. Lou, 2018: Unraveling the relationships between boundary layer height and $\mathrm{PM}_{2.5}$ pollution in China based on four-year radiosonde measurements. Environ. Pollut., 243, 1186-1195, https://doi.org/ 10.1016/j.envpol.2018.09.070.

Mokarizadeh, A., R. F. Mohammad, A. R. Mohammad, and A. Mohammad, 2015: A comprehensive review of pesticides and the immune dysregulation: Mechanisms, evidence and consequences. Toxicol. Mech. Methods, 25, 258-278, https:// doi.org/10.3109/15376516.2015.1020182.

Nagy, A., and I. Jahn, 2019: Advanced data acquisition system for wind energy applications. Period. Polytech. Transp. Eng., 47, 124-130, https://doi.org/10.3311/PPtr.11515.

NASEM, 2018a: Thriving on Our Changing Planet: A Decadal Strategy for Earth Observation from Space. National Academies Press, 716 pp., https://doi.org/10.17226/24938.

_ 2018b: The Future of Atmospheric Boundary Layer Observing, Understanding, and Modeling: Proceedings of a Workshop. National Academies Press, 48 pp., https://doi.org/10.17226/ 25138.

National Research Council, 2009: Observing Weather and Climate from the Ground Up: A Nationwide Network of Networks. National Academies Press, 250 pp., https://doi.org/10.17226/ 12540.

Nelson, K. N., J. M. Boehmler, A. Y. Khlystov, H. Moosmüller, V. Samburova, C. Bhattarai, E. M. Wilcox, and A. C. Watts, 2019: A multipollutant smoke emissions sensing and sampling instrument package for unmanned aircraft systems: Development and testing. Fire, 2, 18, https://doi.org/10.3390/fire2020032.

Ochoa-Hueso, R., and Coauthors, 2017: Ecological impacts of atmospheric pollution and interactions with climate change in terrestrial ecosystems of the Mediterranean Basin: Current research and future directions. Environ. Pollut., 227, 194-206, https://doi.org/10.1016/j.envpol.2017.04.062.

Pillar-Little, E. A., and Coauthors, 2021: Observations of the thermodynamic and kinematic state of the atmospheric boundary layer over the San Luis Valley, CO using the CopterSonde 2 remotely piloted aircraft system in support of the LAPSE-RATE field campaign. Earth Syst. Sci. Data, 13, 269-280, https://doi.org/ 10.5194/essd-13-269-2021.

Reuder, J., P. Brisset, M. Jonassen, M. Müller, and S. Mayer, 2009: The Small Unmanned Meteorological Observer SUMO: A new tool for atmospheric boundary layer research. Meteor. Z., 18, 141-147, https://doi.org/10.1127/0941-2948/2009/0363.

_, L. Båserud, S. Kral, J. W. Wagenaar, and A. Knauer, 2016: Proof of concept for wind turbine wake investigations with the RPAS SUMO. Energy Procedia, 94, 452-461, https://doi.org/ 10.1016/j.egypro.2016.09.215.

San-Miguesl-Ayanz, J., J. D. Carlson, M. Alexander, K. Tolhurst, G. Morgan, R. Sneeuwjagt, and M. Dudley, 2003: Current methods to assess fire danger potential. Wildland Fire Danger Estimation and Mapping, E. Chuvieco, Ed., World Scientific, 21-61.

Sarim, M., M. Radmanesh, M. Dechering, M. Kumar, R. Pragada, and K. Cohen, 2019: Distributed detect-and-avoid for multiple unmanned aerial vehicles in national air space. J. Dyn. Syst. Meas. Control, 141, 071014, https://doi.org/10.1115/1.4043190.

Schroeder, J. L., W. S. Burgett, K. B. Haynie, I. Sonmez, G. D. Skwira, A. L. Doggett, and J. W. Lipe, 2005: The West Texas 
Mesonet: A technical overview. J. Atmos. Oceanic Technol., 22, 211-222, https://doi.org/10.1175/JTECH-1690.1.

Segales, A. R., B. R. Greene, T. M. Bell, W. Doyle, J. J. Martin, E. A. Pillar-Little, and P. B. Chilson; 2020: The CopterSonde: An insight into the development of a smart UAS for atmospheric boundary layer research. Atmos. Meas. Tech., 13, 2833-2848, https://doi.org/10.5194/amt-13-2833-2020.

Sengupta, P., and R. Banerjee, 2014: Environmental toxins: Alarming impacts of pesticides on male fertility. Hum. Exp. Toxicol., 33, 1017-1039, https://doi.org/10.1177/0960327113515504.

Song, J., W. Yang, Z. Li, Y. Higano, and X. Wang, 2016: Discovering the energy, economic and environmental potentials of urban wastes: An input-output model for a metropolis case. Energy Convers. Manage., 114, 168-179, https://doi.org/ 10.1016/j.enconman.2016.02.014.

Stewart, A. E., J. K. Lazo, R. E. Morss, and J. L. Demuth, 2012: The relationship of weather salience with the perceptions and uses of weather information in a nationwide sample of the United States. Wea. Climate Soc., 4, 172-189, https://doi.org/10.1175/ WCAS-D-11-00033.1.

Sullivan, J. T., and Coauthors, 2019: The ozone water-land environmental transition study: An innovative strategy for understanding Chesapeake Bay pollution events. Bull. Amer. Meteor. Soc., 100, 291-306, https://doi.org/10.1175/ BAMS-D-18-0025.1.

Tao, W., and Coauthors, 2020: Aerosol pH and chemical regimes of sulfate formation in aerosol water during winter haze in the North China Plain. Atmos. Chem. Phys., 20, 11 729-11 746, https://doi.org/10.5194/acp-20-11729-2020.

Thistle, H. W., 2004: Meteorological concepts in the drift of pesticide. Proc. Int. Conf. on Pesticide Application for Drift Management, Waikoloa, HI, Washington State University Extension, 156-162.

Tripp, D. D., E. R. Martin, and H. D. Reeves, 2021: Applications of uncrewed aerial vehicles (UAVs) in winter precipitation-type forecasts. J. Appl. Meteor. Climatol., 60, 361-375, https:// doi.org/10.1175/JAMC-D-20-0047.1.

Vasquez, K. T., J. D. Crounse, B. C. Schulze, K. H. Bates, A. P. Teng, L. Xu, H. M. Allen, and P. O. Wennberg, 2020: Rapid hydrolysis of tertiary isoprene nitrate efficiently removes $\mathrm{NO}_{\mathrm{x}}$ from the atmosphere. Proc. Natl. Acad. Sci. USA, 117, $33011-$ 33 016, https://doi.org/10.1073/pnas.2017442117.

Vömel, H., and Coauthors, 2018: NCAR/EOL Community Workshop on Unmanned Aircraft Systems for Atmospheric Research. UCAR/NCAR Earth Observing Laboratory Final Rep., 80 pp., https://doi.org/10.5065/D6X9292S.
Wang, G., and Coauthors, 2016: Persistent sulfate formation from London Fog to Chinese haze. Proc. Natl. Acad. Sci. USA, 113, 13 630-13 635, https://doi.org/10.1073/pnas.1616540113.

Wharton, S., and J. K. Lundquist, 2010: Atmospheric stability impacts on power curves of tall wind turbines-An analysis of a West Coast North American wind farm. Lawrence Livermore National Laboratory Tech. Rep. LLNL-TR-424425, 73 pp., https:// llnl.primo.exlibrisgroup.com/discovery/delivery/01LLNL_INST: 01LLNL_INST/1246057460006316?lang=en.

Williamson, G. J., D. M. J. S. Bowman, O. F. Price, S. B. Henderson, and F. H. Johnston, 2016: A transdisciplinary approach to understanding the health effects of wildfire and prescribed fire smoke regimes. Environ. Res. Lett., 11, 125009, https://doi.org/ 10.1088/1748-9326/11/12/125009.

Yan, J., T. Zhao, and J. Kang, 2016: Sensitivity analysis of technology and supply change for $\mathrm{CO}_{2}$ emission intensity of energy-intensive industries based on input-output model. Appl. Energy, 171, 456-467, https://doi.org/10.1016/j.apenergy.2016.03.081.

Zanchi, G., and M. V. Brady, 2019: Evaluating the contribution of forest ecosystem services to societal welfare through linking dynamic ecosystem modelling with economic valuation. Ecosyst. Serv., 39, 101011, https://doi.org/10.1016/j.ecoser.2019.101011.

Zhao, Z., and Coauthors, 2019: The influence of multi-scale atmospheric circulation on severe haze events in autumn and winter in Shanghai, China. Sustainability, 11, 5979, https://doi.org/10.3390/ su11215979.

Zielke, B. S., 2011: A procedure for obtaining high-density in-situ measurements of ozone concentration within the planetary boundary layer. M.S. thesis, School of Meteorology, University of Oklahoma, $129 \mathrm{pp}$.

Ziolkowska, J. R., 2018: Economic value of environmental and weather information for agricultural decisions-A case study for Oklahoma Mesonet. Agric. Ecosyst. Environ., 265, 503512, https://doi.org/10.1016/j.agee.2018.07.008.

- 2019: Economic benefits and evaluation of mesonet information and tools-Example of OK-FIRE. Seventh Symp. on the Weather, Water, and Climate Enterprise, Phoenix, AZ, Amer. Meteor. Soc., 1.2., https://ams.confex.com/ams/2019Annual/ webprogram/Paper351133.html.

__ , and J. Zubillaga, 2018: Importance of weather monitoring for agricultural decision-making-An exploratory behavioral study for Oklahoma Mesonet. J. Sci. Food Agric., 98, 49454954, https://doi.org/10.1002/jsfa.9027.

- and Coauthors, 2017: Benefits and beneficiaries of the Oklahoma Mesonet-A multisectoral ripple effect analysis. Wea. Climate Soc., 9, 499-519, https://doi.org/10.1175/WCAS-D-16-0139.1. 